\title{
RELATEDNESS AND ACQUIRER PERFORMANCE
}

\section{Lasse B. Lien and Peter G. Klein}

\section{ABSTRACT}

While the strategic management literature suggests that related diversification is superior to unrelated diversification, there is little evidence that acquirers benefit from pursuing related targets. We argue that the empirical literature is plagued by poor measures of relatedness. Moreover, many empirical studies do not control adequately for the characteristics of the market for corporate control. We argue that not only value creation, but also value appropriation, depend on the relatedness of acquirer and target. Using an improved measure of relatedness, we provide empirical evidence that acquirer returns are positively and significantly correlated with relatedness.

\section{INTRODUCTION}

Resource-based and capabilities theories of the firm suggest that diversification can add value when the firm's activities are closely related (Montgomery \& Wernerfelt, 1988; Prahalad \& Hamel, 1990; Rumelt, 1974; Wernerfelt, 1984). However, there is little evidence that acquirers benefit from pursuing related, rather than unrelated, targets (Datta, Pinches, \& Narayanan, 1992; Kaplan \& Weisbach, 1992; Lubatkin, 1987; Seth, 1990;

Advances in Mergers and Acquisitions, Volume 5, 9-24

Copyright $(C) 2006$ by Elsevier Ltd.

All rights of reproduction in any form reserved

ISSN: 1479-361X/doi:10.1016/S1479-361X(06)05001-0 
Singh \& Montgomery, 1987; Sirower, 1997). Some studies even find a negative correlation between acquirer returns and the relatedness of acquirer and target (Agrawal, Jaffe, \& Mandelker, 1991). The overall consensus appears to be that even if relatedness creates value, the additional value is largely captured by target shareholders, leaving little gain for the acquiring firm.

We question this consensus for two reasons. First, relatedness is difficult to measure. Most studies use the distance between SIC codes, or the FTC's categories of "product extension," "market extension," and "conglomerate," to measure the relatedness of pairs of business units. However, such measures are not derived from theoretical models of scope, spillovers, experimentation, or other reasons for diversification, and are probably poor proxies for the kinds of relatedness that matter for value creation (Robins \& Wiersema, 1995, 2003; Markides \& Williamson, 1996; Silverman, 1999; Lien $\&$ Klein, 2004, 2005). Second, the acquirer's returns depend not only on value creation, but value appropriation, which depends on the characteristics of the market for corporate control. As explained by Barney (1988), acquirers benefit from acquisitions when (a) the acquisition creates unique and valuable synergies, (b) the acquirer has private information about the combined value of acquirer and target, (c) the acquirer is lucky, or (d) there are more targets than acquirers. Ignoring luck, we argue that the remaining three conditions are more likely to obtain in related transactions. Assuming relatedness is properly measured, then, acquirers pursuing related targets should be in a better position to appropriate a share of the value created by the transaction.

The chapter proceeds as follows. We begin by discussing the conditions under which relatedness creates create value. Next, we evaluate common measures of relatedness, asking if they are sensitive to these conditions. Third, we outline the relation between value appropriation and relatedness. Finally, we supply some preliminary evidence that when an improved measure of relatedness is substituted for conventional SIC-based measures, there is a positive and significant relationship between relatedness and acquirer performance.

\section{RELATEDNESS AND VALUE CREATION}

Do diversifying acquisitions create value? The answer depends on whether combining particular business activities within a firm provides performance advantages unavailable to single-business firms or firms with other combi- 
nations of activities. In the resource-based view, value is created when resources useful in one industry are substitutes for, or complements to, resources useful in another industry. ${ }^{1}$ Substitute resources are those developed in one industry that is functional substitutes for resources developed in another industry. Complementary resources exist when there are positive spillovers between resources used in different industries. Without such complementarities - either static or dynamic - it is hard to make economic sense of relatedness. ${ }^{2}$ However, while substitutability or complementarity are necessary conditions for relatedness to enhance performance, they are not sufficient conditions, as we argue below.

\subsection{Resource Substitutability}

Consider resources that are substitutes across industries (leading to economies of scope). If resources are perfectly divisible, then substitutability provides no advantage to a related diversifier. However, if resources are not perfectly divisible, ${ }^{3}$ then single-business firms or unrelated diversifiers will be left with costly excess capacity, which can be exploited through related diversification (Willig, 1979). Penrose (1959) was one of the first writers to relax the assumption of perfect divisibility. She noted that excess capacity arises not only because some resources are inherently indivisible (e.g., half a truck is not half as valuable as a truck), but also due to learning; accumulated production generates new resources along with excess capacity in existing resources. These learning effects, combined with resource indivisibilities, suggest that related diversification can improve performance (assuming that unused capacity is costly).

However, as Teece $(1980,1982)$ points out, while the existence of such indivisibilities explains joint production, it does not explain why joint production must be organized within a single firm. If the excess capacity created by indivisibilities can be traded in well functioning markets, single-business firms and unrelated diversifiers can simply sell or rent out their excess capacity or buy the capacity they need from others. In other words, absent transactional difficulties, two separate firms could simply contract to share the inputs, facilities, or whatever accounts for the relevant scope economies. If they do not, it must be because the costs of writing or enforcing such a contract are greater than the benefits from joint production. Whether the firms will create value by integrating thus depends on the comparative costs and benefits of contracting, not on the underlying production technology. Indeed, if contracting costs are low, the related diversifier may actually 
compete at a disadvantage relative to the single-business firm, because the diversified firm faces the additional bureaucratic costs of low-powered incentives, increased complexity, and so on.

\subsection{Resource Complementarity}

More recent attention has focused not on resource substitutability, but resource complementarity (Christensen \& Foss, 1997; Foss \& Christensen, 2001; Larsson \& Finkelstein, 1999; Teece, Rumelt, Dosi, \& Winter, 1994). Complementarities exist when investment in one industry increases the value of resources used in another industry, or when decisions about resource use in one industry affect similar decisions in another. These positive spillovers create a quantitative and qualitative coordination problem which may be best managed within a diversified firm (Milgrom \& Roberts, 1992; Richardson, 1972). As before, to explain why this coordination problem cannot be solved in the market (i.e., between single-business firms or unrelated diversifiers), we must appeal to some form of contracting costs. Hence, transaction costs are also relevant to situations involving complements.

Recently literature emphasizes dynamic complementarities, the ability to identify new ways of combining existing resources or speed up the development of new resources. ${ }^{4}$ The benefits to similarity in this context arise because such dynamic complementarities may be greater if the industries in question share some basic features (March, 1991), or because some common characteristics facilitate their exploitation (Finkelstein \& Haleblian, 2002; Prahalad \& Bettis, 1985). The degree of dynamic complementarity between industries thus depends on the balance between variety and similarity (Christensen \& Foss, 1997). Industries with appropriate balances between variety and similarity produce larger dynamic complementarities than industries that are too different or too similar. Empirically, this implies that portfolios of businesses with strong inter-industry complementarities should be considered related (or, in Teece et al.'s, 1994 language, "coherent"), and that firms with related activities should outperform firms with unrelated combinations of activities and single-business firms, ceteris paribus (again, assuming positive contracting costs). 


\section{CONVENTIONAL MEASURES OF RELATEDNESS}

Most of the empirical work in mergers and acquisitions use either the SIC system or the FTC's merger classification system to label transactions as either related or unrelated (conglomerate). The simplest SIC-based measures label a transaction related if the firms' core businesses share the same twodigit SIC code and unrelated otherwise (e.g., Doukas \& Kan, 2004). Other approaches label transactions related if any of the firms' largest businesses share a four-digit SIC code (e.g, Morck, Shleifer, \& Vishny, 1990). The most sophisticated versions use distances between SIC codes to compute continuous measures of relatedness. Finkelstein and Haleblian (2002), for example, consider up to six lines of businesses for each firm They assign scores of two, four, and six if the primary businesses match on the two-digit, threedigit, and four-digit levels, respectively. Comparison of the secondary businesses yields scores of one, two, and three for matches on the two-digit, three-digit, and four-digit levels, respectively.

Such continuous measures have obvious advantages over discrete ones, not only because the former allow for more sophisticated econometric analysis, but also because, conceptually, relatedness is a matter of degree. ${ }^{5}$ Even these SIC-based measures are problematic, however. One problem is that the SIC's four-digit system allows only four levels of distance. No matter how the weighting scheme is devised, the four available distance categories are different two-digit SIC codes, same two-digit SIC codes, same three-digit SIC codes, and same four-digit SIC codes. ${ }^{6}$ The underlying distance measure is in other words not truly continuous. In effect, this imposes the rather brave assumption that any pair of industries equally distant within the SIC hierarchy are equally dissimilar.

However, the most serious problem with measures based on SIC codes is that these measures do not capture indivisibilities and transaction costs, the conditions under which relatedness creates value. Because these conditions are not incorporated into conventional measures of relatedness, these measures will tend to exaggerate relatedness in cases where resources are close substitutes but these additional conditions are not met. Moreover, as pointed out by Larsson and Finkelstein (1999) and Foss and Christensen (2001), SIC-based procedures have an implicit bias toward economies of scope and against dynamic complementarities, suggesting that specific types of relatedness are systematically underestimated. For these reasons, even the best SIC-based measures have serious limitations for studying relatedness and value creation. 
Evidence of these problems can be observed in the data on diversification. A good measure of diversification patterns is the frequency with which a given pair of industries is combined inside a firm, compared to what one would expect if diversification patterns were random (Teece et al., 1994). Assuming that firms tend to combine industries that are related, this difference can be interpreted as a measure of relatedness. If the difference is large and positive, then the industries in question are closely related. If the difference is negative, then the industries are unrelated. Table 1 provides this measure for all four-digit industry pairs that were combined within firms during the 1980s. Our source is the AGSM/Trinet database, a detailed, establishment-level dataset covering all US firms (Voigt, 1993). Table 1 shows how this measure correlates to an SIC measure in which industry pairs in the same three-digit SIC code are given a value of 3 , industries in the same two-digit SIC code are given a value of 2 , and industries in different

Table 1. Correlation between SIC Distances and Actual Patterns of Diversification.

\begin{tabular}{|c|c|c|c|c|c|c|}
\hline & & \multirow{2}{*}{$\begin{array}{c}\text { SIC } \\
\text { Distance }\end{array}$} & \multicolumn{4}{|c|}{ Actual Combinations } \\
\hline & & & 1981 & 1983 & 1985 & 1987 \\
\hline SIC distance & $\begin{array}{l}\text { Pearson } \\
\quad \text { correlation } \\
\text { Sig. (two-tailed) } \\
N\end{array}$ & 1 & & & & \\
\hline $\begin{array}{l}\text { Actual } \\
\text { combinations } \\
1981\end{array}$ & $\begin{array}{l}\text { Pearson } \\
\quad \text { correlation } \\
\text { Sig. (two-tailed) } \\
N\end{array}$ & $\begin{array}{l}0.320(* *) \\
0.000 \\
122,105\end{array}$ & 122,105 & & & \\
\hline $\begin{array}{l}\text { Actual } \\
\text { combinations } \\
1983\end{array}$ & $\begin{array}{l}\text { Pearson } \\
\quad \text { correlation } \\
\text { Sig. (two-tailed) } \\
N\end{array}$ & $\begin{array}{l}0.327(* *) \\
0.000 \\
133,868\end{array}$ & $\begin{array}{l}0.941(* *) \\
0.000 \\
113,061\end{array}$ & 133,868 & & \\
\hline $\begin{array}{l}\text { Actual } \\
\text { combinations } \\
1985\end{array}$ & $\begin{array}{l}\text { Pearson } \\
\quad \text { correlation } \\
\text { Sig. (two-tailed) } \\
N\end{array}$ & $\begin{array}{l}0.322(* *) \\
0.000 \\
126,993\end{array}$ & $\begin{array}{l}0.895(* *) \\
0.000 \\
96,707\end{array}$ & $\begin{array}{l}0.930(* *) \\
0.000 \\
109,232\end{array}$ & 126,993 & \\
\hline $\begin{array}{l}\text { Actual } \\
\text { combinations } \\
1987\end{array}$ & $\begin{array}{l}\text { Pearson } \\
\quad \text { correlation } \\
\text { Sig. (two-tailed) } \\
N\end{array}$ & $\begin{array}{l}0.338(* *) \\
0.000 \\
12,5297\end{array}$ & $\begin{array}{l}0.834(* *) \\
0.000 \\
58,897\end{array}$ & $\begin{array}{l}0.857(* *) \\
0.000 \\
64,325\end{array}$ & $\begin{array}{l}0.889(* *) \\
0.000 \\
67,728\end{array}$ & 125,297 \\
\hline
\end{tabular}

$N$ refers to the number of four-digit industry pairs actually combined inside a firm. 
two-digit industries are given a value of 1 . As seen in the table, the correlation between observed diversification patterns and the SIC-based relatedness measure is surprisingly low, ranging from 0.32 to 0.338 . More detailed analysis also shows that some of the most frequently combined industry pairs are not related according to the SIC system. For example, the most frequently combined industries, Offices of Physicians (8011) and Outpatient Care Facilities (8081), do not share the same three-digit SIC code, though they are obviously closely related businesses. Other industry pairs in the top $1 \%$ in terms of observed combinations are not even in the same twodigit SIC code, such as Deep Sea Foreign Transportation (4411) and Freight Transportation Arrangement (4723), and Wood Cabinets for Television (2517) and Radio, Phonography and Cathode Ray Television Tubes (3672). Conversely, many industry pairs sharing a three-digit SIC code were never once combined during this period. This raises not only theoretical, but also empirical, concern about the reliability of SIC-based measures.

The FTC classification system was used in several studies published in the 1980s and early 1990s (Chatterjee, 1986; Elgers \& Clark, 1980; Lubatkin, 1983, 1987; Seth, 1990a, b; Park, 2003), but the FTC's Large Merger Series was discontinued in 1979. The FTC classified mergers as horizontal if the merging firms were in the same product market, product extension if there were functional similarities in production or distribution (without direct competition), market extension if the parties sold similar products in different geographical markets, vertical if the firms were actual or potential trading partners, and other/conglomerate if none of these conditions held. Most studies using these classifications collapsed the categories into horizontal, vertical, and conglomerate, or simply related and conglomerate. ${ }^{7}$ These measures unfortunately suffer from the same problems as those based on SIC codes. Moreover, as the FTC classifications cannot be converted into continuous measures, they are also less flexible. Finally, the reliability of the FTC's classifications depends on the judgment of the FTC's staff. Because we know little about how these judgments were rendered, it is impossible to verify the means used to classify complex mergers into mutually exclusive categories.

\section{VALUE APPROPRIATION AND RELATEDNESS}

Our argument so far is that relatedness is likely to create value only when specific conditions are present, and that existing measures of relatedness do not adequately capture these conditions. To understand acquirer returns, 
however, we must focus not only on value creation, but also value appropriation. Barney (1988) argued that acquirers (of any type) can earn supranormal returns only when the market for corporate control is not perfectly competitive. This could occur if a particular bidder and target make a unique combination and if the source of this unique value is not easily imitated. Alternatively, the bidder may have private information about the value of the combined firm. ${ }^{8}$ Finally, bidders can appropriate value if the number of targets is larger than the number of bidders.

Are these conditions more likely to hold when bidder and target are related? First, consider the case in which a particular combination of firms creates unique value that is not easily imitated. We assume that unrelated acquirer-target pairs seek value creation opportunities associated with generic resources, while related acquirer-target pairs seek value creation opportunities associated with specific resources. Montgomery and Wernerfelt (1988, p. 625) argue that generic resources "normally yield less advantage because they are in wider supply ... [M]any firms have the opportunity to develop factors that apply to many different industries (e.g., teams of general managers), whereas fewer firms have natural opportunities to create more specific factors (e.g., teams of biochemists)." This suggests that the equalizing forces are stronger with respect to generic factors, and consequently that generic factors tend to be more evenly distributed across firms than specific factors. Because unique value creation opportunities requires heterogeneity, bidders pursuing related targets are more likely to be able to generate unique value than bidders pursuing unrelated targets. Moreover, bidders pursuing related targets can often realize the gains associated with the target's generic resources, while bidders pursuing unrelated targets cannot realize the gains associated with the target's specific resources, giving related bidders an edge in bidding contests. For these reasons, we expect unique and inimitable value creation opportunities to be more likely for related bidders, and that the bidding process should systematically select for such bidders when they are present.

Next, consider the case of private information about opportunities to create value. The likelihood of discovering such opportunities should be increasing in the acquirer's knowledge about the target firm and its markets, and firms in related industries - possibly with overlapping technology, customers or suppliers - are likely to know more about the target firm and its markets. Put differently, private knowledge about opportunities for value creation is more likely to be discovered by firms in a related industry.

Finally, consider the relative number of bidders and targets. The bidder's bargaining position is strongest when there are more targets than bidders. 
The more generic the source of the value creation opportunity with the target, the fewer the restrictions on the number of potential bidders. The bidder could essentially come from any industry. Consequently it becomes more likely that many bidders will be competing for the same target. Conversely, if the value creation opportunity derives from the specific resources, the number of potential bidders is likely to be smaller. In addition, it is possible that a value creation opportunity based on specific resources can be realized with several (or all) firms in the target industry, while a value creation opportunity of a more generic type may only be relevant for a particular target (with particular needs or shortcomings). The point here is that the ratio of potential bidders to potential targets should tend to be higher in unrelated transactions.

For these reasons, the conditions specified by Barney (1988) as necessary for acquirers to appropriate value are more likely to obtain when acquirers are pursuing related targets. Of course, these advantages are mitigated by the market for corporate control, so at least some related acquirers will not earn abnormal returns. Still, we expect to find a positive relationship between acquirer returns and relatedness, given that relatedness is properly measured.

\section{PRELIMINARY EMPIRICAL EVIDENCE}

\subsection{An Alternative Measure of Relatedness}

It is one thing to criticize discrete measures based on SIC codes or FTC categories, another to provide a better one. We propose as a possible candidate the survivor-based measure that produced the patterns of diversification summarized Table 1. As described above, this procedure measures relatedness by comparing the observed combinations of activities within firms to what one would expect if diversification patterns were random. Here the knowledge of local decision makers and the screening function of competitive markets reveal what activities are related. Moreover, such a measure is both holistic and flexible, holistic in the sense that it captures all aspects of relatedness relevant for performance, including the conditions specified in Section 2 above, and flexible in the sense that it allows the causes of relatedness to vary from case to case. Of course, the survivor-based approach assumes that local decision makers possess the relevant information and incentives to make good decisions about resource combinations and/or that the competitive selection process effectively corrects for errors. How- 
ever, attempts to evaluate the survivor-based approach empirically find it better than SIC-based schemes in a variety of dimensions (Lien \& Klein, 2004, 2005).

Another concern is that by allowing the market to determine what activities are related, we are left not knowing precisely what relatedness is in each specific case (a limitation shared by SIC-based procedures). Nevertheless, such an approach may still reveal what relatedness does, in how it affects other variables of interest, such as acquirer returns in mergers and acquisitions.

The discussion above suggests the following two hypotheses:

H1. Relatedness will not be positively associated with acquirer returns when relatedness is measured with SIC distances.

H2. Relatedness will be positively associated with acquirer returns when relatedness is measured with the survivor-based approach.

\subsection{Methods}

To test these hypotheses we first calculate a survivor-based measure of relatedness for all US industry pairs using the AGSM/Trinet Large Establishment Database (Trinet). The Trinet database contains records of all US establishments with more than 20 employees, including variables such as four-digit SIC code, corporate ownership, and sales. By aggregating the establishments for each parent in each four-digit SIC code, and the different four-digit SIC codes for each parent, and different parents for each fourdigit SIC industry, we get a comprehensive picture of diversification patterns in the US economy. Comparison with the Census of Manufacturers indicate that Trinet contains 95\% of all establishments it should (Voigt, 1993), and that omissions are most likely for small firms (which are less likely to be diversified).

Following Teece et al. (1994) we use the following procedure: Let $K$ be the number of diversified firms in the economy. Let $J_{i j}$ be a count of how often industries $i$ and $j$ are actually combined within the same firm. $J_{i j}$ will be larger if industries $i$ and $j$ are related, but will also increase with the number of firms in the two industries $\left(n_{i}\right.$ and $\left.n_{j}\right)$ To remove the effect of the size of industries $i$ and $j$, the number $J_{i j}$ is compared with the number of expected combinations if diversification patterns were random. The random diversification hypothesis can be operationalized as a hypergeometric situation where a sample of size $n_{i}$ is drawn (without replacement) from a population of $K$ firms. Those chosen are considered active in industry $i$. A second 
independent sample of size $n_{j}$ is then drawn from the population of $K$ firms. Those chosen are considered active in industry $j$. The number $x_{i j}$ of firms active in both $i$ and $j$ is then a hypergeometric random variable with population $K$, special members $n_{i}$ and sample size $n_{j}$. The distribution function for this variable is then:

$$
\operatorname{Pr}\left(X_{i j}=x\right)=f_{h g}\left(x, K, n_{i}, n_{j}\right)=\frac{\left(\begin{array}{c}
n_{i} \\
x
\end{array}\right)\left(\begin{array}{c}
K-n_{i} \\
n_{j}-x
\end{array}\right)}{\left(\begin{array}{l}
K \\
n_{j}
\end{array}\right)}
$$

The mean and variance of $X_{i j}$ are

$$
\begin{gathered}
\mu_{i j}=E\left(X_{i j}\right)=\frac{n_{i} n_{j}}{K} \\
\sigma^{2}=\mu_{i j}\left(1-\frac{n_{i}}{K}\right)\left(\frac{K}{K-1}\right)
\end{gathered}
$$

A standardized measure of the relatedness between industries $i$ and $j$ is then constructed based on the difference between $J_{i j}$ and $\mu_{i j}$ in the following fashion:

$$
\text { Survivor Relatedness } i j=\frac{J_{i j}-\mu_{i j}}{\sigma_{i j}}
$$

The measure Survivor Relatedness $i j$ is thus a standardized measure of how much actual combinations exceed expected combinations under the random diversification hypothesis. ${ }^{9}$

Next, we draw a sample of transactions from the Thompson/SDC Platinum database from 1982 to 1985 . We include only those transactions in which the acquirer acquires full ownership, both acquirer and target are listed in Compustat, the transaction has an "effective date" (to ensure it was completed), acquirer and target are have different primary four-digit SIC codes, and data are available from CRSP to compute cumulative abnormal returns (CARs). This yields 72 transactions.

We calculate Acquirer $C A R$ and Target $C A R$ using a $[-30,+30]$ event window and the CRSP equally weighted index as the market proxy. SIC Relatedness is calculated as follows: if the two firms share the same primary three-digit SIC code, a value of 3 is assigned; if they share the same primary two-digit SIC code, a value of 2 is assigned; and if they are in different primary two-digit SIC codes, a value of 1 was assigned. The variable Sur- 
vivor Relatedness uses the logic presented above to assign a survivor-based measure of the relatedness between the parties' primary businesses. Note that we use the survivor-based measure for only 1981 and 1983 in our study (AGSM/Trinet data is only available biannually). To mitigate endogeneity the 1981 measures are used for merger announcements in 1982 and 1983, and the 1983 measures for announcements in 1984 and 1985.

Table 2 presents means, standard deviations, and correlations for the key variables. The sample has a mean Target $C A R$ of 0.29 and, a mean Acquirer $C A R$ of -0.02 , comparable to figures reported in other studies covering the same period.

\subsection{Findings}

Table 3 reports a series of standardized OLS regressions of Acquirer $C A R$ on measures of relatedness. Model 1 uses only Target $C A R$ as a regressor; we interpret its coefficient as a proxy for the premium paid to selling shareholders. The coefficient is positive, but not statistically significant. Model 2 adds SIC Relatedness. Adding this variable does not improve the model significantly; the coefficient on SIC Relatedness is not statistically significant, nor is the $F$ value for the regression itself. This is consistent with Hypothesis 1, the claim that acquirer returns are unrelated to relatedness, when relatedness is measured using SIC distances.

Model 3 substitutes Survivor Relatedness for SIC Relatedness, leading to a substantial improvement in the model. The coefficient on Survivor Relatedness is positive and statistically significant and the $F$ value is also significant. We interpret this as evidence for Hypothesis 2, the acquirer returns are positively related to survivor-based relatedness. Finally, in model 4 we

Table 2. Means, Standard Deviations and Correlation Coefficients $(n=72)$.

Mean SD Target CAR SIC Relatedness Survivor Relatedness

\begin{tabular}{lrrlll}
\hline Acquirer CAR & -0.02 & 0.19 & 0.16 & 0.18 & $0.27^{* *}$ \\
Target CAR & 0.29 & 0.31 & 1 & 0.10 & 0.01 \\
SIC Relatedness & 1.40 & 0.68 & & 1 & $0.47^{* * *}$ \\
Survivor Relatedness & 12.57 & 16.26 & & & 1 \\
\hline
\end{tabular}

$* p<0.1$

$* * p<0.5$

$* * * p<0.01$. 
Table 3. Standardized Regressions on Acquirer CAR $(n=72)$.

\begin{tabular}{lcccc}
\hline & Model 1 & Model 2 & Model 3 & Model 4 \\
\hline Target CAR & 0.159 & 0.143 & 0.156 & 0.151 \\
SIC Relatedness & & 0.167 & & 0.052 \\
Survivor relatedness & & & $0.266^{* *}$ & $0.241^{*}$ \\
Adj $R^{2}$ & 0.012 & 0.026 & 0.070 & 0.059 \\
$F$ & 1.842 & 1.962 & $3.715^{* *}$ & $2.5^{*}$ \\
\hline
\end{tabular}

$* * * p<0.01$

${ }^{*} p<0.1$

$* * p<0.5$

include both SIC Relatedness and Survivor Relatedness to see if the two measures capture different, complementary aspects of relatedness. However, adding SIC Relatedness lowers the $F$ - and adjusted $R^{2}$-values and the SIC variable itself is not statistically significant. Hence SIC Relatedness does not seem to add useful information not already captured by Survivor Relatedness. Put differently, the two measures appear to be substitutes, with Survivor Relatedness being the better measure.

\section{DISCUSSION AND CONCLUSIONS}

Our main point in this chapter is that the empirical literature on relatedness and acquirer returns is affected by limitations in the way relatedness is usually measured. Conventional measures are inconsistent with underlying theories about how relatedness can increase value, and our preliminary empirical work shows that an alternative measure of relatedness - one that accounts for the complexity of factors determining the value of relatedness leads to different results.

Of course, the empirical analysis presented here is merely suggestive and does not constitute a thorough investigation of the relationship between survivor-based relatedness and value creation. The analysis would benefit from the inclusion of additional control variables and a more detailed breakdown of the business portfolios of the merging firms. Nonetheless, our preliminary findings suggest that future research on mergers and acquisitions should seek to incorporate more sophisticated measures of relatedness. We think the survivor-based approach is one of the most promising alternatives. 


\section{UNCITED REFERENCES}

Agrawal, Jaffe, \& Mandelker (1992); Foss, Foss, Klein, \& Klein; Prahalad \& Bettis (1986); Richards (1972).

\section{NOTES}

1. Throughout the paper we use the term "resources" to include both resources and competences.

2. Because we are discussing diversifying acquisitions we ignore gains related to increases in market share or improvements in market positioning. Such gains are unlikely to come from acquisitions across industries. We also ignore here the "internal capital markets" explanation for unrelated acquisitions (Hubbard \& Palia, 1999; Klein, 2001).

3. In this we include as a special case the situation where the resource in question is a public input, so that excess capacity will always exist.

4. Foss, Foss, Klein, and Klein (2005) describe this ability - organizing heterogeneous capital resources under conditions of Knightian uncertainty - as the key characteristic of entrepreneurship.

5. Finkelstein and Haleblian (2002) find a positive and significant relationship between acquirer performance and their continuous measure of relatedness.

6. The one-digit SIC level is usually disregarded because it is considered too highly aggregated to convey any information about relatedness. We are unaware of any studies using six-digit NAICS codes.

7. As pointed out by Seth (1990b) the FTC categories were collapsed in different ways, making it hard to compare findings across studies.

8. Barney adds to this condition a requirement that the combination creates a unique value. However, as long as the information about the firms' combined value is private, this requirement is not necessary - other potential bidders will not act on information they do not have.

9. Note that this is the same measure we termed Actual Combinations in Table 1.

\section{ACKNOWLEDGMENT}

We thank Carl Voigt for sharing the AGSM/Trinet database.

\section{REFERENCES}

Agrawal, A., Jaffe, J. F., \& Mandelker, G. N. (1992). The post-merger performance of acquiring firms - a reexamination of an anomaly. Journal of Finance, 47(4), 1605-1621. 
Barney, J. B. (1988). Returns to bidding firms in mergers and acquisitions - reconsidering the relatedness hypothesis. Strategic Management Journal, 9, 71-78.

Chatterjee, S. (1986). Types of synergy and economic value - the impact of acquisitions on merging and rival firms. Strategic Management Journal, 7(2), 119-139.

Christensen, J. F., \& Foss, N. J. (1997). Dynamic corporate coherence and competence based competition: Theoretical foundations and strategic implications. In: A. Heene \& R. Sanchez (Eds), Competence-based strategic management. Chichester: Wiley.

Datta, D. K., Pinches, G. E., \& Narayanan, V. K. (1992). Factors influencing wealth creation from mergers and acquisitions - a metaanalysis. Strategic Management Journal, 13(1), $67-84$.

Doukas, J. A., \& Kan, O. B. (2004). Excess cash flows and diversification discount. Financial Management, 33(2), 71-88.

Elgers, P. T., \& Clark, J. J. (1980). Merger types and shareholder returns - additional evidence. Financial Management, 9(2), 66-72.

Finkelstein, S., \& Haleblian, J. (2002). Understanding acquisition performance: The role of transfer effects. Organization Science, 13(1), 36-47.

Foss, K., Foss, N. J., Klein, P. G., \& Klein, S. The entrepreneurial organization of heterogeneous capital. Journal of Management Studies (forthcoming).

Foss, N. J., \& Christensen, J. F. (2001). A market-process approach to corporate coherence. Managerial and Decision Economics, 22, 213-226.

Hubbard, R. G., \& Palia, D. (1999). A reexamination of the conglomerate merger wave in the 1960s: An internal capital markets view. Journal of Finance, 54(3), 1131-1152.

Kaplan, S. N., \& Weisbach, M. S. (1992). The success of acquisitions - evidence from divestitures. Journal of Finance, 47(1), 107-138.

Klein, P. G. (2001). Were the acquisitive conglomerates inefficient? Rand Journal of Economics, 32(4), 745-761.

Larsson, R., \& Finkelstein, S. (1999). Integrating strategic, organizational, and human resource perspectives on mergers and acquisitions: A case survey of synergy realization. Organization Science, 10(1), 1-26.

Lien, L. B., \& Klein, P. G. (2004). Yet another way of measuring relatedness - this one: Let competition do it! Best paper proceedings of the Academy of Management annual meeting, New Orleans.

Lien, L. B., \& Klein, P. G. (2005). Measuring inter-industry relatedness: SIC-distances vs. the survivor principle. Best paper proceedings of the Academy of Management annual meeting, Honolulu, Hawaii.

Lubatkin, M. (1983). Mergers and the performance of the acquiring firm. Academy of Management Review, 8(2), 218-225.

Lubatkin, M. (1987). Merger strategies and stockholder value. Strategic Management Journal, $8(1), 39-53$.

Markides, C. C., \& Williamson, P. J. (1996). Corporate diversification and organizational structure: A resource-based view. Academy of Management Journal, 39(2), 340-367.

Milgrom, P., \& Roberts, J. (1992). Economics, organization and management. Englewood Cliffs, NJ: Prentice-Hall.

Montgomery, C. A., \& Wernerfelt, B. (1988). Diversification, Ricardian rents, and Tobin- $Q$. Rand Journal of Economics, 19(4), 623-632.

Morck, R., Shleifer, A., \& Vishny, R. W. (1990). Do managerial objectives drive bad acquisitions. Journal of Finance, 45(1), 31-48. 
Park, C. (2003). Prior performance characteristics of related and unrelated acquirers. Strategic Management Journal, 24(5), 471-480.

Penrose, E. (1959). The theory of the growth of the firm. Oxford: Blackwell.

Prahalad, C. K., \& Bettis, R. A. (1986). The dominant logic - a new linkage between diversity and performance. Strategic Management Journal, 7(6), 485-501.

Prahalad, C. K., \& Hamel, G. (1990). The core competence of the corporation. Harvard Business Review, 68(3), 79-91.

Richards, Gb. (1972). Organisation of industry. Economic Journal, 82(327), 883-896.

Robins, J., \& Wiersema, M. F. (1995). A resource-based approach to the multibusiness firm empirical-analysis of portfolio interrelationships and corporate financial performance. Strategic Management Journal, 16(4), 277-299.

Robins, J. A., \& Wiersema, M. F. (2003). The measurement of corporate portfolio strategy: Analysis of the content validity of related diversification indexes. Strategic Management Journal, 24(1), 39-59.

Rumelt, R. P. (1974). Strategy, structure, and economic performance. Division of Research Graduate School of Business Administration Harvard University.

Seth, A. (1990). Sources of value creation in acquisitions - an empirical-investigation. Strategic Management Journal, 11(6), 431-446.

Seth, A. (1990). Value creation in acquisitions - a reexamination of performance issues. Strategic Management Journal, 11(2), 99-115.

Silverman, B. S. (1999). Technological resources and the direction of corporate diversification: Toward an integration of the resource-based view and transaction cost economics. Management Science, 45(8), 1109-1124.

Singh, H., \& Montgomery, C. A. (1987). Corporate acquisition strategies and economic-performance. Strategic Management Journal, 8(4), 377-386.

Sirower, M. L. (1997). The synergy trap: How companies lose the acquisition game. New York: Free Press.

Teece, D. J. (1980). Economies of scope and the scope of the enterprise. Journal of Economic Behavior \& Organization, 1(3), 223-247.

Teece, D. J. (1982). Towards an economic-theory of the multiproduct firm. Journal of Economic Behavior \& Organization, 3(1), 39-63.

Teece, D. J., Rumelt, R., Dosi, G., \& Winter, S. (1994). Understanding corporate coherence theory and evidence. Journal of Economic Behavior \& Organization, 23(1), 1-30.

Voigt, C. W. (1993). The Trinet large establishment data. Anderson Graduate School of Management, University of California at Los Angeles: California.

Wernerfelt, B. (1984). A resource-based view of the firm. Strategic Management Journal, 5(2), 171-180.

Willig, R. D. (1979). Multiproduct technology and market structure. American Economic Review, 69(2), 346-351. 